\title{
Mulheres Negras: Epistemologias do Presente
}

\section{APRESENTAÇÃO}

$\mathrm{Na}$ seção temática Mulheres Negras: Epistemologias do Presente as organizadoras trazem uma parceria-aliança entre intelectuais negras insubmissas comprometidas com processos de produção de conhecimento que tem causado uma 'fratura epistêmica' no empreendimento hegemônico branco, masculino, misógino, heteropatriarcal e transfóbico que historicamente organiza a acadêmica aqui e alhures. Esse conjunto de artigos de mulheres negras intelectuais nos mostra também em que ponto estamos nesse jogo complexo de disputa no interior desses ambientes de produção científica. Mulheres Negras: Epistemologias do Presente nos coloca em contato com um instigante ambiente de inovação teórica e analítica que nos faz reafirmar como temos produzido corajosamente a partir de múltiplas formas de 'saberfazer.' Em tempos tão marcados pelo racismo, sexismo, misoginia e LGBTQI+fobias,

\footnotetext{
${ }^{1}$ Aline MARTINS- Doutoranda pelo programa de Pós-graduação em Educação Proped/Uerj. Mestre em Educação Uerj/ProPEd. Integra o grupo de estudos de gênero, sexualidade e $(\mathrm{m})$ interseccionalidades na educação e(m) saúde (GENI). É Graduada e Licenciada em Ciências sociais (UFRJ) e professora de Sociologia pela Rede estadual no Rio de janeiro

${ }^{2}$ Valeria Lima de Almeida é graduada em Letras - Português/Inglês, tradutora e mestranda pelo Programa de Pós-Graduação em Linguística Aplicada (PIPGLA/UFRJ).

${ }^{3}$ Carla Ramos Munzanzu - Antropóloga e Coordenadora do Departamento de Antropologia da Universidade Federal do Oeste do Pará (UFOPA); PhD em Estudos Africanos e da Diáspora Africana pela Universidade do Texas (Austin). Coordenadora do Grupo de Pesquisa e Documentação das Expressões Afro-religiosas do Oeste do Pará e Caribe (NPDAFRO).
} 


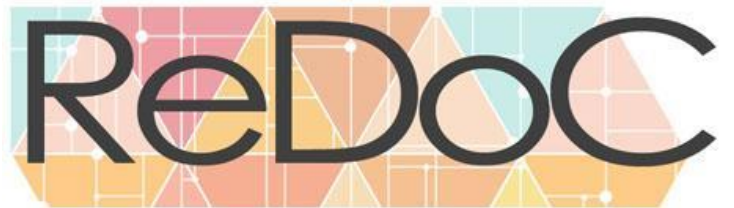

\section{Revista Docência e Cibercultura}

uma Edição como esta evidencia que os "nossos passos e insubmissão epistemológica vêm de longe."

Abrindo essa Seção o artigo, "PUNKS, SAPATONAS E WELFARE QUEENS POTENCIAL RADICAL DA POLÍTICA QUEER”, de Valeria Lima de Almeida traz pela primeira vez uma versão em língua portuguesa realizada por uma intelectual e tradutora negra, do importante artigo de Cathy J. Cohen originalmente publicado no livro Black Queer Studies: A Critical Anthology (2005), organizado por E. Patrick Johnson e Mae G. Henderson. Tal antologia crítica marca uma mudança profunda mudança de compreensão no interior dos chamados 'Queer Studies' e 'Black Studies e Africana Studies'. A obra traz uma perspectiva político-analítica e ativista de conteúdo fortemente interseccional que contribui com a consolidação de um campo acadêmico compreendido como 'Black Queer Studies' nos Estados Unidos. Essa 'fusion' ganha especial definição justamente nos artigos de E.Patrick Johnson e Mae G. Henderson Queering Black Studies/ "Quaring” Queer Studies, e na brilhante análise de Cathy J. Cohen a respeito dos limites que um Política Queer encontra dentro de uma abordagem normativa que não considera, ou melhor, que não tem aproximação suficiente com outras identidades marginalizadas, e grupos sociais subalternizados como negras e negros das classes trabalhadoras cujas expressões de sexualidade e de gênero escapam necessariamente da hegemonia heteronormativa. Heteronormatividade, que de acordo com o argumento de Cathy Cohen, precisa ser compreendida como um conjunto de práticas e de aparatos institucionais que a "normalizam" e "legitimam, privilegiando relações do tipo heterossexual. Refletindo num ambiente de crise aguda pela epidemia da AIDS dentro dos movimento gay, das política neoliberais dos governos neoliberais de Ronald Reagan e Bill Clinton, Cohen questiona o potencial radical de uma política " "Queer" à luz das teses do Feminismo Negro e sobretudo das teses das intelectuais e ativistas negras e lésbicas que influenciaram fortemente o pensamento crítico dos anos de 1970 até 1990. PUNKS, SAPATONAS E WELFARE QUEENS - POTENCIAL RADICAL DA POLÍTICA QUEER, na sua versão em português, torna-se leitura acessível e obrigatória para todes interessades nesse debate instigante e urgente.

O artigo, EXPERIÊNCIAS INTERSECCIONAIS COTIDIANAS: UM ENCONTRO ENTRE MULHERES NEGRAS E PERIFÉRICAS, de Danielle do Nascimento Oliveira Oliveira, discute a experiência de mulheres negras utilizando o referencial teórico do chamado "feminismo negros diaspórico". A proposta de pesquisa investiga os diálogos, negociações e tensões que surgem no "encontro" com define a autora, de mulheres negras com a Universidade Pública. A análise interseccional de Danielle do Nascimento Oliveira encontra ecos no artigo "INTELECTUALIDADE NEGRA EM AÇÃO: 
ENTRE O NÃO LUGAR E O PROTAGONISMO NA PRODUÇÃO DE SABERES", de Sulamita Rosa da Silva que articula o conceito de outside/within forjado pela socióloga Afroamericana Patricia Hill Collins. Em sua tradução do conceito e de sua aplicabilidade, a autora discorre a respeito da experiência de mulheres negras como "sujeitas políticas", transitando dentro de universos sociais distintos e hierarquicamente distantes, mas guardando a sua posicionalidade como "uma de fora." É justamente essa "experiência de trânsito" que vai nos deixar compreender como a realidade social é permeada de opressões históricas, sociais e culturais. Fazendo uso de sua própria trajetória de vida como um elemento importante na sua produção intelectual, a autora traz a sua sala de aula como locus para sua experimentação teórica e política e de escrevivência.

Em "MULHERES E CRIANÇAS AFRODESCENDENTES NAS ARTES VISUAIS BRASILEIRAS: IMAGENS-NARRATIVAS EDUCAM", Francilene Brito da Silva Correio, indaga a respeito das imagens-narrativas: Imagens educam? Como educam? Que educações podemos tecer no curso da vida com imagens? Quais usos podemos fazer/sentir/teorizar com imagens enquanto práticas educativas nas fronteiras de nós mesmas, enquanto mulheres e crianças afrodescendentes? $E$, Sandra Rita de Cássia Roza, no seu artigo "VOCÊ É UMA RAINHA": CANTORAS NEGRAS E SUAS AUTORREPRESENTAÇÕES DE RAINHAS EM VIDEOCLIPES" faz uma análise do discurso das obras de cantoras negras brasileiras e estadunidenses, para discutir representação e política de identidade negra. Para tanto, ela investiga um ponto em comum, a auto representação da mulher negra como "rainhas", nas obras "Menina Pretinha" de Mc Soffia, "Ouça-me Rmx" de Tássia Reis, "É o poder" de Karol Conká, "Moment 4 Life" de Nicki Minaj e "Love on the brain", de Rihanna.

Um conjunto de belos textos aborda aspectos fundamentais para a compreensão do que chamamos de Diáspora africana e suas expressões políticas: que é o corpo negro, sua presença e suas 'cartografias insubmissas' como nomeia a intelectual negra Denise Carrascosa. Abrindo espaços para uma investigação corajosa a respeito de professoras negras e de suas performances políticas no espaço escolar, Aline Correia Martins, em DARIA A MINHA VIDA A QUEM ME DESSE O TEMPO: PENSANDO O CORPO DA NEGRA E MULHER NO ESPAÇO PÚBLICO E ESCOLAR" indaga sobre o corpo da mulher negre nos espaços públicos, e convida para uma reflexão dos espaços públicos e como estes se relacionam com o corpo feminino negre. $\mathrm{O}$ artigo utiliza as categorias de cor, gênero e classe para pensar o espaço de ensino e as interações com alunes e profissionais da educação na Baixada fluminense, no Rio de Janeiro. 
A autora Tatiana Santos da Paz Correio em seu trabalho "PROCESSOS FORMATIVOS DE UMA PESQUISADORA NEGRA NO CAMPO DA CIBERCULTURA E EDUCAÇÃO: IMPLICAÇÕES E TRAJETÓRIAS", apresenta uma análise que considera as maneiras pelas quais mulheres negras têm desafiado as representaçõe subalternizantes produzidas pelo ambiente estrutural racista sobre 0 corpo negro com o uso de artefatos digitais. Além disso, a autora, que se baseia numa escrita de experiência para fundamentar a sua perspectiva de investigação, demonstra no seu texto como esses processos de ressignificação atravessaram a sua própria história de vida, constituindo uma "experiência formativa" como pesquisadora negra no campo da cibercultura e educação. Jessica Mara Raul em sua investigação "ENTRE SILÊNCIOS E PROTESTOS: UMA REFLEXÃO SOBRE ESCRITA PRETA NO CIBERESPAÇO", nos ensina sobre uma ciência política negra dedicada a entender o "ciberespaço" como um território cada vez mais importante para a articulação de mulheres negras. Dessa maneira, a autora observa como as representaçõe sobre negritude e gênero no Brasil vem sendo reconfiguradas por uma "pedagogia negra" forjada por mulheres negras nas redes sociais, de modo a interromper as representações estereotipadas sobre si mesmas e a comunidade negra no Brasil.

A seção Mulheres Negras: Epistemologias do Presente apresenta um panorama de debates que se debruça sobre aspectos da experiência política e histórica de mulheres negras na diáspora africana, tomando pontos da diáspora africana como locus de análise tal qual Brasil e Estados Unidos. Estes artigos inauguram temáticas e inovam em procedimentos metodológicos e analíticos trazendo para o centro do campo de pesquisas sobre relações raciais uma abertura para os feminismos negros, para diferentes referências intelectuais como Conceição Evaristo, Chimamanda Ngozi Adichie, Ana Maria Gonçalves, Patrícia Hill Collins, Karol Conká, Rihanna, que informam uma compreensão mais acurada do lugar ocupado pelo Brasil no interior dos estudos da diáspora africana. Particularmente, os dois artigos que seguem enfatizam a dimensão histórica e política sobre a experiência de mulheres negras na diáspora. No texto "UM DEFEITO DE COR" E A NECESSIDADE DE DEBATER A ESCRAVIDÃO DA MULHER NEGRA NA EDUCAÇÃO BÁSICA", as autoras Telma Rocha, Cleyton Williams Golveia da Silva Brandão e Isla Silva de Jesus tomam a escravidão a escravidão da mulher negra no Brasil e suas metamorfoses enquanto sujeito político. Tomando com fonte de investigação a obra de Ana Maria Gonçalves, "Um Defeito de Cor" (2011), o artigo se dedica a compreender o que chama de "sequelas" causadas pela exploração de corpos de mulheres negras na produção de imagens desumanizantes que precisam 


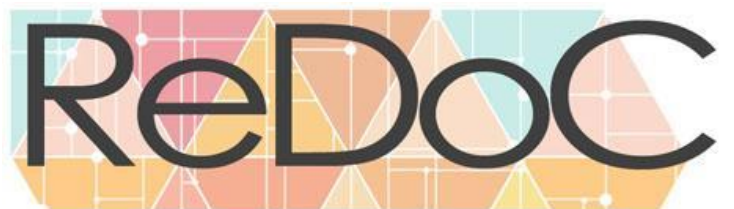

\section{Revista Docência e Cibercultura}

ser fortemente questionadas também no interior dos sistemas de ensino. Nas palavras das autoras, a "criticidade sobre as concepções da falsa superioridade de raças impostas no século XVI e ratificadas pela sociedade contemporânea resulta na reflexão do espaço da mulher negra, de sua luta cotidiana e do seu poder de ruptura de fundamentos do patriarcado brasileiro. Dentro disse, elas concluem afirmando da "importância de revisitar questões, como a descolonização na educação básica brasileira." As autoras Silvia Campos Paulino e Simone Campos Paulino em "TRANÇANDO IDENTIDADES: O CABELO DA MULHER NEGRA EM ESSE CABELO DE DJAIMILIA PEREIRA DE ALMEIDA E AMERICANAH DE CHIMAMANDA NGOZI ADICHIE", parte da leitura atenta de duas obras de mulheres negras, uma delas Brasileira e a outra Nigeriana: Esse Cabelo: $A$ tragicomédia de um cabelo crespo que cruza fronteiras (2015), de Djaimilia Pereira de Almeida e Americanah (2014) de Chimamanda Ngozi Adichie, para discutir identidade e processos de descolonização e desconstrução de autoimagens marcadas por um repertório racial e sexista precário e subjugador da experiência de mulheres negras. Com uma análise da obra de Franz Fanon e outros autores contemporâneos, esse artigo indaga sobre os constructos identitários de sujeitos subalternos, pós-modernos e pós-coloniais, tomando a problemática da subjetividade de mulheres negras na diáspora moderna.

\section{1 - "A FORÇA ANCESTRAL FEMININA NO MAR DE IEMANJÁ - UM FOTOARTIGO" - Cristiano Sant'Anna de Medeiros}

Pensar em fotografia é pensar em arte, é pensar em lembrança do vivido e do momento mágico eternizado em uma ou mais imagens. Cotidianamente, milhares de imagens são produzidas e circulam todos os dias nos vários meios de comunicação, seja na televisão, no cinema, nos espaços públicos e privados, nas redes sociais da internet, em nossa casa, nossa vida... Imagens estão, o tempo todo, à nossa volta, e constituem um dos mais importantes modos pelos quais vemos, aprendemos, pensamos, narramos e tecemos o presente. Pensando que as imagens estão a nossa volta e são potentes na nossa contemporaneidade, este artigo fotográfico aqui denominado de "fotoartigo", pretende trazer imagens fotográficas para homenagear a força ancestral feminina, representada aqui pela Orixá lemanjá (Rainha do mar, mãe de todos os Orixás) Os Orixás são ancestrais africanos divinizados pelas forças da natureza tal como a água do mar, dos rios, das chuvas, dos raios, dos trovões, dos ventos... Orixá é força, é vida, é presente, é sabedoria, é conhecimento, é epistemologia do presente, passado e do futuro. 
12 - Seção "Ponto de vista": "MULHERES NEGRAS NA POLÍTICA: O FUTURO É UMA MULHER PRETA" de Mônica Francisco.

13 - Seção "Ensaios": Edna Balbina dos Anjos dos Santos sobre "MEMÓRIAS QUE REINSCRECEM: O USO DA MEMÓRIA NA RECONSTRUÇÃO IDENTITÁRIA DO QUILOMBO BAIXA GRANDE".

O trabalho discute memória como ferramenta de reconhecimento da identidade. Se trata da auto atribuição de comunidade negra, onde os questionamentos dos mais jovens e o conhecimento dos mais velhos se alinharam ressignificando a identidade quilombola.

14 - Seção "Resenha": Alexandra Lima da Silva e Sarah Soanirina Ohmer discutem sobre "RESENHANDO AUTORAS NEGRAS: FEMINISTAS, PLURAIS E DIASPÓRICAS".

Este texto realiza um mapeamento de edições de autoras do pensamento feminista negro dos Estados Unidos e a circulação de tais livros no mercado editorial brasileiro. Procura compreender os significados do movimento de publicação de autoras negras no Brasil. O texto conclui que a emergência da autoria de mulheres negras no Brasil é um processo permeado pelas relações desiguais e pela necessidade de enfrentar lógicas heteronormativas, masculinas e eurocentradas. Resenhar obras de mulheres negras evidência um campo fértil, com repertórios plurais e diaspóricos.

15 - Seção de "Vídeo-Pesquisa": "WEBSÉRIE 'FALA PRETA: VOZES DO PRESENTE - MULHERES QUE INSPIRAM MULHERES'" de Bruno Olivatto, Denise Guerra e Edilene Santana

'Fala Preta: vozes do presente - mulheres que inspiram mulheres' é uma websérie audiovisual, de curta-metragem, estruturada em 05 episódios, produzida pelo Centro de Estudos e Assessoria Pedagógica/CEAP, ONG fundada pelos Jesuítas, atuante há 26 anos na cidade de Salvador, Bahia. A obra é resultante de edital público, executado no ano 2019, promovido pela Secretaria de Promoção da Igualdade Racial/SEPROMI, do Governo do Estado da Bahia. A iniciativa intenciona visibilizar, por amplificação das vozes de mulheres negras, suas percepções sobre questões de gênero, raça, classe, sexualidade, saúde, empreendedorismo, entre outros temas que orbitam diretamente o seu cotidiano das relações sociais. Esta produção audiovisual foi precedida de rodas temáticas de conversa, contando com a participação de 40 mulheres negras, por 12 encontros presenciais físicos, ao longo de 03 meses, realizados na sede do CEAP. A websérie 'Fala Preta' é produto cultural de valorização das histórias de vida dessas mulheres, trazendo realce de suas narrativas críticas e testemunhos diários de superação, bem como acentua protagonismos e (re)existências empreendidas em seus diferentes e desafiadores contextos sociais, 


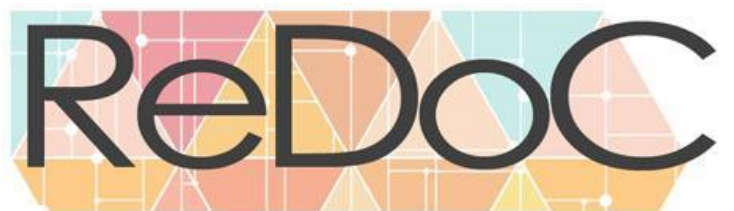

\section{Revista Docência e Cibercultura}

desde o familiar ao profissional, passando pelas suas relações com a escola, com movimentos sociais e suas práticas de sobrevivência material e existencial. Trata-se de dispositivo formativo acionador de reflexões em torno, especialmente, de questões como machismo, sexismo, patriarcado, racismo estrutural, entre outros.

16 - Na seção "Produções Artísticas, Literárias e Culturais", encontramos os artigos: "MEU BAOBÁ GENEALÓGICO: HISTÓRIAS E MEMÓRIAS DE MULHERES QUE ME SUSTENTAM" - Joselina da Silva

Este texto nasce inicialmente elaborado para uma apresentação no Ler, festival do leitor, realizado na Biblioteca Parque e no Campo de Santana, no dia 20 de novembro, do corrente ano, no Rio de Janeiro. Integrei a mesa intitulada escrituras negras: ancestralidade, memória e autoconhecimento. Tive a grande honra de compartilhar a fala com as professoras Carolina Rocha e Janete Santos Ribeiro. A simbologia e representatividade da data - onde é celebrado o dia da Consciência Negra - me levaram a desejar homenagear as mulheres negras que tem contribuído para minha trajetória acadêmica e de vida. Interessava-se também oportunizar reflexões, embora breves, sobre a história recente do movimento de mulheres negras no Rio de Janeiro. Venho, há algum tempo, me debruçando a respeito dos estudos e reflexões sobre autoetnografia. Assim, decidi recorrer - de forma inspiradora, embora sem citar os autores - a esta teoria ainda pouco aprofundada, no Brasil, para dar apoio às minhas reflexões sobre as mulheres com as quais tenho dialogado e assimilado seus conhecimentos, desde a infância.

\section{REFERÊNCIAS}

COHEN, Cathy; ALMEIDA, Valeria Lima de. PUNKS, SAPATONAS E WELFARE QUEENS - POTENCIAL RADICAL DA POLÍTICA QUEER? Revista Docência e Cibercultura, v. 3, n. 3, set-dez, 2019, p. 21-58. DOI: https://doi.org/10.12957/redoc.2019.46807

CORREIO, Danielly Christina de Souza Mezzari. AMAR É TER UMA ÉTICA AFETIVA, É TER ESSE CUIDADO COM O OUTRO: NARRATIVAS SOBRE AMORES E LESBIANIDADES. Revista Docência e Cibercultura, v. 3, n. 3, set-dez, 2019, p. 361-363. DOI: https://doi.org/10.12957/redoc.2019.47417

CORREIO, Francilene Brito da Silva. MULHERES E CRIANÇAS AFRODESCENDENTES NAS ARTES VISUAIS BRASILEIRAS: IMAGENS-NARRATIVAS EDUCAM. Revista Docência e Cibercultura, v. 3, n. 3, set-dez, 2019, p. 92-104. DOI: https://doi.org/10.12957/redoc.2019.47236

CORREIO, Tatiana Santos da Paz Correio. PROCESSOS FORMATIVOS DE UMA PESQUISADORA NEGRA NO CAMPO DA CIBERCULTURA E EDUCAÇÃO: IMPLICAÇÕES E TRAJETÓRIAS. Revista Docência e Cibercultura, v. 3, n. 3, set-dez, 2019, p. 150-165. DOI: https://doi.org/10.12957/redoc.2019.47246 


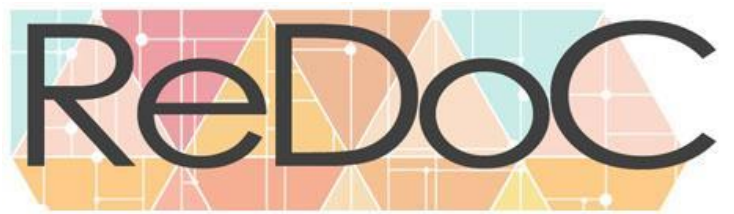

\section{Revista Docência e Cibercultura}

FRANCISCO, Mônica. MULHERES NEGRAS NA POLÍTICA: O FUTURO É UMA MULHER PRETA. Revista Docência e Cibercultura, v. 3, n. 3, set-dez, 2019, p. 232-234. DOI:

https://doi.org/10.12957/redoc.2019.47058

MARTINS, Aline Correia. DARIA A MINHA VIDA A QUEM ME DESSE O TEMPO: PENSANDO O CORPO DA NEGRA E MULHER NO ESPAÇO PÚBLICO E ESCOLAR. Revista Docência e Cibercultura, v. 3, n. 3, set-dez, 2019, p. 128-149. DOI: https://doi.org/10.12957/redoc.2019.45668

MEDEIROS, Cristiano Sant'Anna de. A FORÇA ANCESTRAL FEMININA NO MAR DE IEMANJÁ - UM FOTOARTIGO. Revista Docência e Cibercultura, v. 3, n. 3, set-dez, 2019, p. 271-285.

DOI: https://doi.org/10.12957/redoc.2019.44965

MENDES, Geoésley Negreiros. FOTONAKIRIGRAFIAS: NARRATIVAS DE UMA ÁFRICA. Revista Docência e Cibercultura, v. 3, n. 3, set-dez, 2019, p. 286-292. DOI: https://doi.org/10.12957/redoc.2019.44038

OLIVEIRA, Danielle do Nascimento Oliveira. EXPERIÊNCIAS INTERSECCIONAIS COTIDIANAS: UM ENCONTRO ENTRE MULHERES NEGRAS E PERIFÉRICAS. Revista Docência e Cibercultura, v. 3, n. 3, set-dez, 2019, p. 59-74. DOI: https://doi.org/10.12957/redoc.2019.44938

OLIVATTO, Bruno; GUERRA, Denise; e SANTANA, Edilene. WEBSÉRIE 'FALA PRETA: VOZES DO PRESENTE - MULHERES QUE INSPIRAM MULHERES'. Revista Docência e Cibercultura, v. 3, n. 3, setdez, 2019, p. 262-262. DOI: https://doi.org/10.12957/redoc.2019.47568

PAULINO, Silvia Campos; e PAULINO, Simone Campos. TRANÇANDO IDENTIDADES: O CABELO DA MULHER NEGRA EM ESSE CABELO DE DJAIMILIA PEREIRA DE ALMEIDA E AMERICANAH DE CHIMAMANDA NGOZI ADICHIE. Revista Docência e Cibercultura, v. 3, n. 3, set-dez, 2019, p. 215-231. DOI: https://doi.org/10.12957/redoc.2019.44720

RAUL, Jessica Mara. ENTRE SILÊNCIOS E PROTESTOS: UMA REFLEXÃO SOBRE ESCRITA PRETA NO CIBERESPAÇO. Revista Docência e Cibercultura, v. 3, n. 3, set-dez, 2019, p. 166-194. DOI:

https://doi.org/10.12957/redoc.2019.44955

ROCHA, Telma Rocha; BRANDÃO, Cleyton Williams Golveia da Silva; e JESUS, Isla Silva de. UM DEFEITO DE COR" E A NECESSIDADE DE DEBATER A ESCRAVIDÃO DA MULHER NEGRA NA EDUCAÇÃO BÁSICA. Revista Docência e Cibercultura, v. 3, n. 3, set-dez, 2019, p. 195-214. DOI:

https://doi.org/10.12957/redoc.2019.47250

ROZA, Sandra Rita de Cássia. "VOCÊ É UMA RAINHA": CANTORAS NEGRAS E SUAS AUTORREPRESENTAÇÕES DE RAINHAS EM VIDEOCLIPES. Revista Docência e Cibercultura, v. 3, n. 3, set-dez, 2019, p. 105-127. DOI: https://doi.org/10.12957/redoc.2019.44300

SANTOS, Edna Balbina dos Anjos dos. MEMÓRIAS QUE REINSCRECEM: O USO DA MEMÓRIA NA RECONSTRUÇÃO IDENTITÁRIA DO QUILOMBO BAIXA GRANDE. Revista Docência e Cibercultura, v. 3, n. 3, set-dez, 2019, p. 155-175. DOI: https://doi.org/10.12957/redoc.2019.44623 


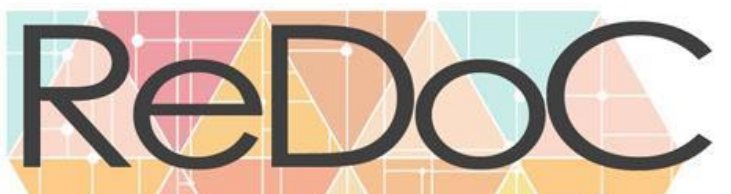

\section{Revista Docência e Cibercultura}

SILVA, Alexandra Lima da; e OHMER, Sarah Soanirina. RESENHANDO AUTORAS NEGRAS: FEMINISTAS, PLURAIS E DIASPÓRICAS. Revista Docência e Cibercultura, v. 3, n. 3, set-dez, 2019, p. 155-175. DOI: https://doi.org/10.12957/redoc.2019.47165

SILVA, Joselina da. MEU BAOBÁ GENEALÓGICO: HISTÓRIAS E MEMORIAS DE MULHERES QUE ME SUSTENTAM. Revista Docência e Cibercultura, v. 3, n. 3, set-dez, 2019, p. 155-175. DOI: https://doi.org/10.12957/redoc.2019.46914

SILVA, Sulamita Rosa da. INTELECTUALIDADE NEGRA EM AÇÃO: ENTRE O NÃO LUGAR E O PROTAGONISMO NA PRODUÇÃO DE SABERES. Revista Docência e Cibercultura, v. 3, n. 3, set-dez, 2019, p. 155-175. DOI: https://doi.org/10.12957/redoc.2019.44995 